\title{
Managing Capacity at a Service Facility: an EXPERIMENTAL APPROACH
}

Carlos A. Delgado-Alvarez ${ }^{\mathrm{a}, 1}$, Ann van Ackere, ${ }^{\mathrm{b}, 2}$, Erik R Larsen ${ }^{\mathrm{c}, 3}$, Santiago Arango-Aramburo ${ }^{\mathrm{d}, 4}$

${ }^{a}$ Faculty of Business, Politecnico Colombiano Jaime Isaza Cadavid, Carrera 48 No. 7-151, Medellin, Colombia

${ }^{\mathrm{b}}$ Faculty of Business and Economics (HEC), University of Lausanne, Quartier UNIL-Dorigny, Bâtiment Anthropole, 1015 Lausanne, Switzerland

${ }^{\mathrm{c}}$ Institute of Management, Università della Svizzera Italiana, Via Buffi 13, 6900 Lugano, Switzerland

${ }^{d}$ Decision Science Department, Universidad Nacional de Colombia, Carrera 80 N. 65-223, bloque M8-211, Medellín, Colombia

\footnotetext{
${ }^{1}$ Corresponding author- Tel.: +57 43197900 ext. 460, E-mail address: cadelgado@elpoli.edu.co

${ }^{2}$ Tel: +41 21692 3454, E-mail address: ann.vanackere@ unil.ch

${ }^{3}$ Tel: +41 58666 4639, E-mail address: erik.larsen@ usi.ch

${ }^{4}$ Tel: +57 4425 5371, E-mail address: saarango@ unal.edu.co
} 


\title{
Managing Capacity at a Service Facility: AN EXPERIMENTAL APPROACH
}

\begin{abstract}
Most research in queuing has focused on the optimisation of performance and equilibrium analysis, with little attention to the understanding of how managers actually make decisions. In this paper, we use an experimental set-up to investigate the decision-making process in a queuing capacity expansion problem, in the presence of capacity adjustment delays. The experiment represents a queuing system with one facility and virtual customers who decide whether or not to patronise the facility. Subjects play the role of facility managers who adjust the facility's service capacity to maximise profits. We analyse the actions of the manager to provide new insights into how their behaviour affects the evolution and success of the service system. Our results identify three types of managers: incremental, lumpy and reactive investors, and indicate that these groups use different decision rules. The first group achieved the best performance, and the last group the worst. While managers' decisions are influenced by the backlog of work and the available service capacity, they do not correctly account for their past, but not-yet-implemented, decisions.
\end{abstract}

Keywords: System dynamics; queuing systems; capacity adjustment management; experimental economics; and behavioural operations management. 


\section{Introduction}

Most research in queuing problems has been focused on the optimisation of performance measures and equilibrium analysis, starting with Naor's seminal paper (Naor 1969). More recent work includes Allon and Federgruen (2008), Bassamboo and Randhawa (2010) and Wang, Debo, Scheller-Wolf and Smith (2010). Little attention has been given to the understanding of how managers actually make capacity decisions on a day to day basis: capacity is either assumed given, or managers make a one-off capacity decision.

In this paper, we consider queuing systems in which customers decide whether or not to join a facility for service based on their perception of waiting time, while managers decide to adjust capacity based on their perception of the backlog of work (i.e., the number of customers waiting for service). The present study builds on the previous work of van Ackere, Haxholdt, and Larsen (2013) on behavioural queuing. We adapt their system dynamics (SD) model as an experimental platform to investigate how subjects, playing the role of a manager in a laboratory environment, manage the capacity of a service facility where the customers' satisfaction depends on the waiting time.

We study the capacity management of a service facility, where managers' decisions take time to be implemented and customers take time to update their perceptions. Our focus is thus on the dynamic process of how managers choose to adapt capacity over time, contrary to Allon and Federgruen (2008), Bassamboo and Randhawa (2010) and Wang et al. (2010) where managers make a one-off capacity decision aimed at optimising an equilibrium situation. The problem is framed as the management of a garage where customers must make an appointment to take their cars. The customers' waiting time runs from the time they make their appointment to the time their car is serviced. The task of the subjects is therefore to manage the capacity (i.e., add or remove capacity) in order to satisfy their current customers and attract potential customers. When subjects decide to increase capacity, the capacity orders materialise after a delivery delay. Similarly, the retirement decisions involve a dismantling delay.

Few experiments in economics and management science study queuing problems. Rapoport, Stein, Parco, and Seale (2004) formulated a queuing problem with endogenously determined arrival rates and state-dependent feedback as a non-cooperative n-person game. These experiments focus on studying behaviour from the point of view of the customers. Subjects, playing the role of car owners who need to take their car to a garage for the emissions control, should decide each period whether or not to join the queue and when to do so. Their findings show that mixed-strategy equilibrium solutions explain the behavioural arrival patterns of customers very well at an aggregated level, but not at the individual level. Subsequently, Seale, Parco, Stein, and Rapoport (2005) extended the work of Rapoport et al. (2004) to non-cooperative n-person games with complete information (i.e., including the information 
of the other group-members). They support Rapoport et al. (2004)'s findings, and conclude that these remain valid as long as congestion is unavoidable and information about group behaviour is not provided. Stein, Rapoport, Seale, Zhang, and Zwick (2007) and Rapoport, Stein, Mak, Zwick, and Seale (2010) performed further experiments to study queuing systems with endogenous arrival rates and batch service. They analyse how customers decide whether to join a queue and when to do so. They conclude that players with experience in a constant capacity batch queuing game converge to equilibrium play on an aggregated level when the service capacity is fixed and commonly known, but not when service capacity changes from round to round. Pazgal and Radas (2008) perform an experimental study to compare customer balking and reneging behaviour to that predicted by queuing theory. They conclude that while the subjects' behaviour is consistent with the predictions (little reneging, balking if the queue exceeds a critical value), the level of balking is suboptimal: on average, the subjects' critical value is too large.

SD models have been used extensively to study different aspects of capacity management problems using an experimental approach. One of the most-studied aspects is supply chain management, with a particular focus on the well-known beer game example with its bullwhip effect, see for instance Sterman (1989a), Villa, Gonçalves, and Arango (2015), and Choi and Messinger (2016). Other studies have focussed on the industry level. For instance, Paich and Sterman (1993) study the "boom and bust" cycle, where sales of a new product first grow exponentially, before falling back to the replacement level. At a national level, Sterman (1989b) studies the economic longwave using a capital investment accelerator model. Arango and Moxnes (2012) show that in the presence of capacity vintages and long delays, price cycles can emerge endogenously. A review of SD models used to perform laboratory experiments can be found in Arango, Castañeda, and Olaya (2012), while Wang and Disney (2016) review more specifically work on the bullwhip effect.

Our work differs from the above in several respects. First, the context we study is different: we consider a service facility with two customer classes (current and potential), and subjects play the role of the manager, not of a customer. Second, we consider a significantly more complicated delay structure than previous work: the two customer types have different reaction times, and the manager faces asymmetric capacity addition and dismantling delays; in the underlying SD model, the manager also had a perception and a decision delay. Third, previous work implicitly assumes that the different model behaviours can be generated by a single decision rule. Based on our results, we argue that generating the behaviours of the different types of investors actually requires using different decision rules.

Our experimental results indicate that subjects can be classified into three types of managers according to the way in which they adjust the service capacity: those who make incremental investments in service capacity; those who make lumpy investments; and those who overreact to 
changes in the backlog by repeatedly adding and removing capacity without any logic. Managers' decisions are influenced by the current backlog of work and the available service capacity, but they do not correctly account for their past decisions, which have not yet been implemented, when making future decisions.

The remaining sections of this paper are organised as follows: first, we briefly describe the SD model used for the experiment, focusing on the adaptations made to the original model. Next, we present the experimental design and discuss the results: we provide a descriptive analysis of the way subjects take their decisions and test the experimental hypothesis. The final section contains our conclusions and suggestions for further work.

\section{A Service Facility Management Model}

The system dynamics queuing model used in this paper was originally proposed by van Ackere et al. (2013) to study the feedback and delay structure involved in the relationship between customers and the manager of a service facility. Customers decide whether or not to use the facility for service, while the manager adjusts the service capacity in order to attract more customers, while at the same time trying to minimise spare capacity. Most queuing models assume that customers only use the service once; they thus do not create expectations about waiting times. However, we consider a situation where customers repeatedly require the same service, i.e., depending on the expected service time they will return to the facility or turn to a competitor. We therefore need to be able to model both feedback processes and expectation formation processes. Given its focus on feedback and lags, System Dynamics (SD) is the most appropriate method to achieve our goals (Sterman, 2000; Morecroft, 2015).

As for any modeling approach, its validity and credibility depends on how well the model captures the main feedback structures (Barlas, 1996). This can be an issue when modeling socio-economic systems, where controversies can arise due to different perspectives and focus of the various stakeholders; a well-known example concerns the World model, see Myrtveit (2005) for details. This issue does not arise in our model, given its stylised nature. Another limitation of the SD approach is its continuous and aggregate nature (perfect mixing hypothesis, Sterman, 2000). For instance, we do not distinguish between individual customers, but instead model flows of customers; all expected customers have the same expected waiting time and so do all the potential customers. While in the underlying SD model investments and divestments were also modeled as continuous processes, in the experiments they are replaced by discrete decisions taken by the subjects.

The causal loop diagram in Figure 1 shows the feedback structure of the actors of the system. The model consists of two sectors, customers (left) and the manager (right), connected by the queue. Customers decide whether to use the facility based on their expectation of the waiting time, while the 
manager decides to adjust the service capacity based on the queue length. Examples of this kind of system include car maintenance facilities, and workers or students who daily patronise a restaurant for lunch. In both examples, customers have no obligation to use the facility and the manager is motivated to encourage customers to use his facility by adjusting its service capacity. The capacity ordering process is described in detail in Figure 2. We next describe the main equations of the model. A notation table is given in appendix A and the full equation listing can be found in appendix B.

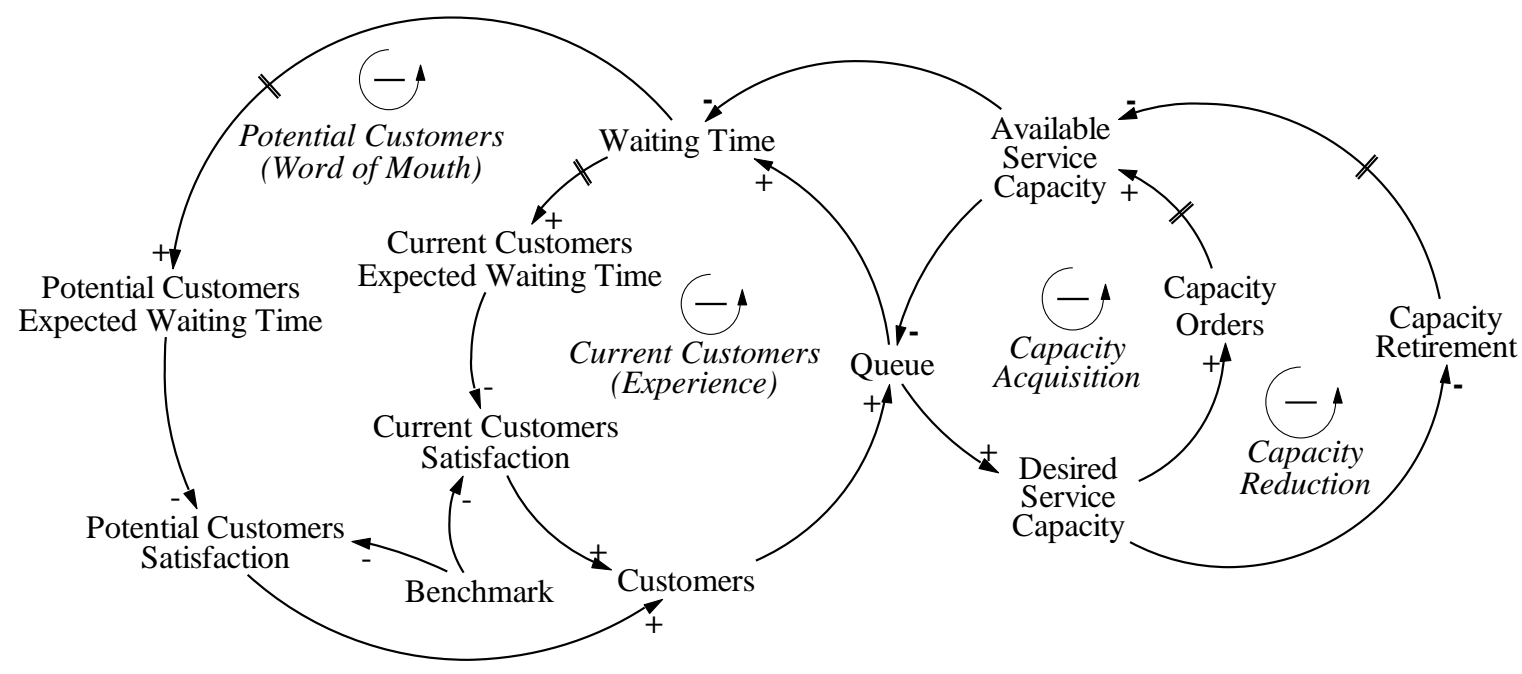

Figure 1. Feedback loop structure for a customer-facility queuing system.

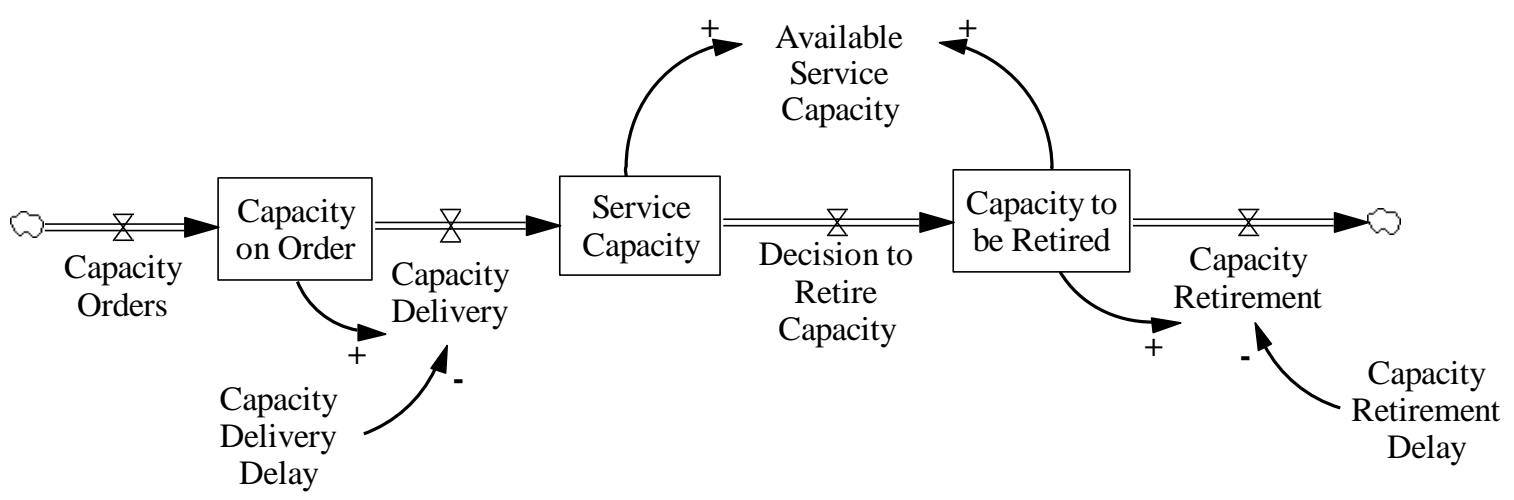

Figure 2. Stock and flow diagram for the capacity management of a service facility.

The number of customers queuing is modelled as the backlog of work which the facility has to serve over the following periods. Given the continuous nature of System Dynamic models, the estimate of the waiting time is considered to be the time between the moment customers make an appointment for service and the moment their service is completed. Once the customers make their appointment they become part of the backlog of customers waiting for service. Thus, the waiting time of these customers depends on the service rate $\left(\mu_{t}\right)$ of the facility. We compute the waiting time $\left(W_{t}\right)$ each period as the ratio between the backlog of customers (i.e., the queue $\left.Q_{t}\right)$ and the service rate $\left(\mu_{t}\right)$ : 


$$
W_{t}=Q_{t} / \mu_{t}
$$

The service rate depends on the service time and the available service capacity $\left(A S C_{t}\right)$. The service time is assumed to be exogenous and fixed, while the available service capacity is endogenous and depends on the manager's decisions. The latter is explained below.

Current customers make up the customer base of the facility; they periodically patronise it as long as they are satisfied, i.e., as long as their expected waiting time $\left(\dot{W}_{t}\right)$ is less than a market reference $\left(\tau_{M R}\right)$, which they consider to be an acceptable waiting time. The market reference is a benchmark, and can be interpreted as a competitiveness index of the facility.

All current customers have the same expected waiting time $\left(\dot{W}_{t}\right)$, which is updated using adaptive expectations:

$$
\dot{W}_{t}=\varphi_{c} W_{t-1}+\left(1-\varphi_{c}\right) \dot{W}_{t-1}
$$

where $\mathrm{W}_{\mathrm{t}}$ denotes the experienced waiting time and $\varphi_{\mathrm{c}}$ is the coefficient that determines the speed of updating. They compare their expected waiting time to the market reference and decide whether or not to stay with this facility.

Potential customers are the prospects of the facility, i.e., customers who the manager considers potentially attractive for the business. They can be either former customers, who left the facility due to dissatisfaction, or new customers who require the service and are looking for a facility. Potential customers decide whether or not to become customers of the facility based on their perceptions about the waiting time. They form their perceptions through word of mouth, using Equation (2), but with parameter $\varphi_{\mathrm{p}}$. Updating perceptions based on the reputation of a facility requires more time than when based on one's own experience. Thus, we assume that the speed at which potential customers update their expectations is lower than that of current customers: $\varphi_{\mathrm{p}}<\varphi_{\mathrm{c}}$.

While customers' expectations determine their loyalty to the facility, potential customers' perceptions determine whether they will try the facility. The lower the waiting time expected by current customers, the more loyal they are. Regarding potential customers, the lower their perceptions, the higher the number who will use the facility. The rates at which new customers join and current customers leave are modelled using nonlinear functions of the satisfaction level. van Ackere et al. (2013) discuss different alternatives to model these functions.

The manager can decide to adjust the service capacity of his facility whenever he wishes, but this adjustment involves an implementation delay, as shown in Figure 2. When the manager decides to add capacity (c.f., capacity orders), these orders accumulate as capacity on order $\left(C O_{t}\right)$ until they are 
available for delivery (c.f., capacity delivery delay). Once the capacity order is fulfilled, the stock of service capacity $\left(S C_{t}\right)$ is increased by the capacity delivery. When the manager decides to withdraw capacity, this capacity is placed as capacity to be retired $\left(C b R_{t}\right)$, but it remains available to customers until it is actually retired at the end of the capacity retirement delay. Hence, the service capacity which the facility has available for service at time $t$ is given by

$$
A S C_{t}=S C_{t}+C b R_{t}
$$

In this way, we can model how the manager accounts for his previous decisions, which have not yet been implemented, when taking his next decision.

\section{A Service Facility Management Experiment}

We use a laboratory experiment to study the way human subjects, taking on the role of a facility manager, deal with a situation in which they must manage the capacity of a service facility. This experiment addresses a common capacity management situation: how to insure the right amount of capacity to perform the service. The experiment is based on the simulation model described above and implemented using a computational graphical interface developed using the Forio Simulation Platform (Forio Online Simulations, 2012).

The setting for the experiment is the management of a large garage. The user interface, shown in Figure 3, is divided into two parts. The first part is an input panel where the subjects indicate their decisions regarding the service capacity. The second part shows the information about the garage subjects receive. This information is updated each time they take a decision, as shown in Figure 3 for a subject who is half-way through the experiment $($ time $=50)$.

Table 1 summarises the parameters and initial conditions for the experiment. Each experimental period represents one month. The garage is initialised with a backlog of 50 customers and an infinite number of potential customers. A car requires at least one period to be serviced (i.e., the minimum time between making an appointment and service completion). Servicing a car yields $\$ 1$ in revenues. Service capacity entails a fixed cost of $\$ 0.5$ per month independently of whether or not it is used. 


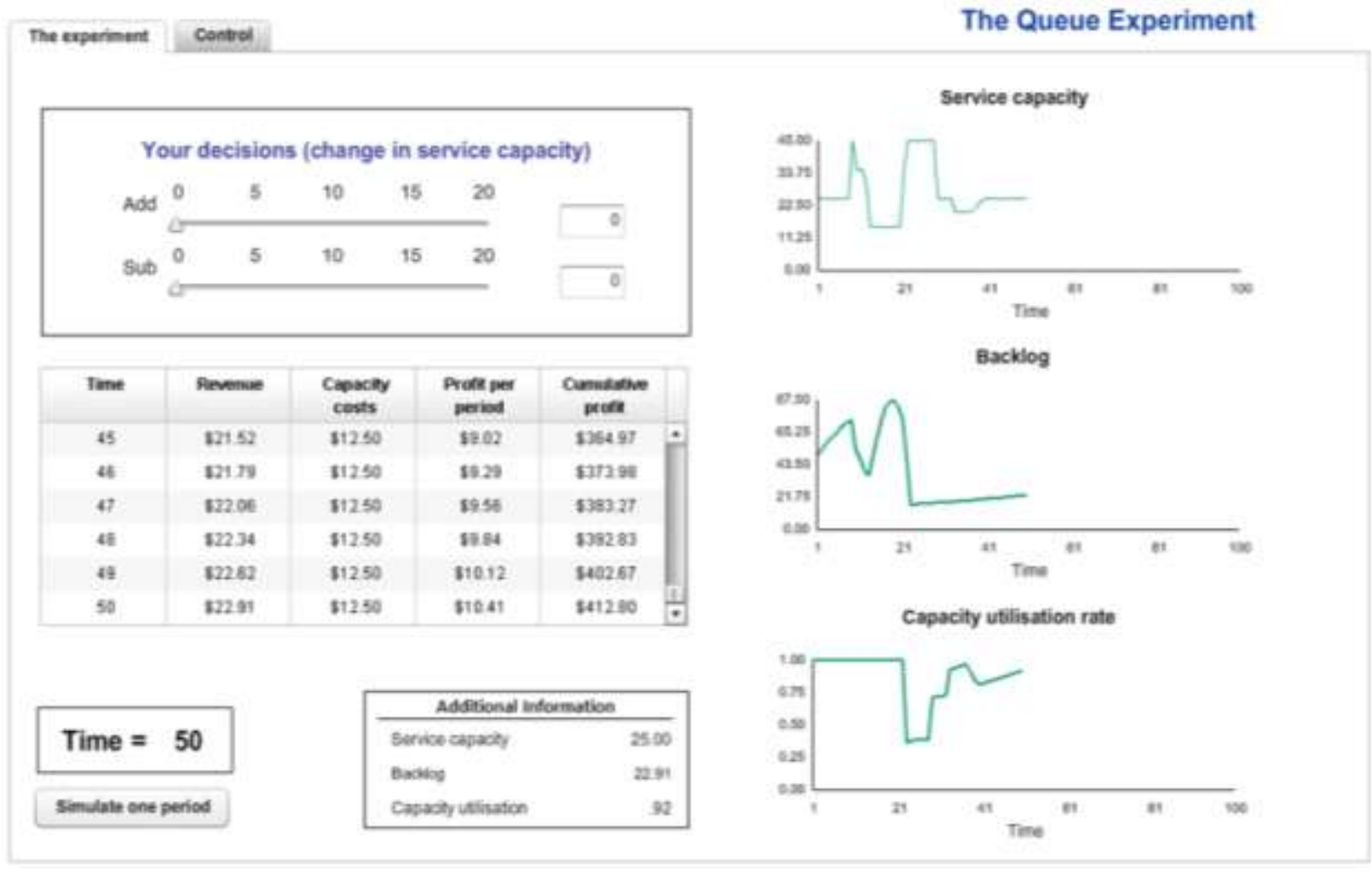

Figure 3. Experimental interface for the service capacity adjustment of a service facility.

\subsection{Experimental Protocol}

We apply the protocols of experimental economics (e.g., Smith, 1982; Friedman \& Sunder, 1994), a methodology used to study the behaviour of human subjects in a controlled economic environment. In behavioural economics, SD models have been widely used to simulate socio-economic environments. Examples include Sterman (1985, 1989a, 1989b), Kampmann and Sterman (2014), and Moxnes (2000). For more details about how SD models are used to carry out laboratory experiments, see Arango et al. (2012).

The experiment was conducted in the informatics laboratories of the School of Business and Economics of the University of Lausanne, Switzerland, were 33 participants were recruited among the undergraduate and master students in Finance, Management and Economics. Subjects received a reward which consisted of two parts. All subjects received a participation fee of CHF 20. Additionally, they received a bonus which varied between CHF 0 and 60, contingent on the total profit they achieved at the end of the experiment. They knew beforehand the payoff scale linking their profits to their bonus. 


\begin{tabular}{lcc}
\hline \hline \multicolumn{1}{c}{ State Variables } & Value & Unit \\
\hline Initial customer base & 175 & People \\
Initial backlog (i.e., Queue) & 50 & People \\
Capacity on order & 0 & People / month \\
Initial service capacity & 25 & People / month \\
Capacity to be retired & 0 & People / month \\
Perceived waiting time of current customers & 2 & Months \\
Perceived waiting time of potential customers & 2 & Months \\
\hline \multicolumn{1}{c}{ Exogenous Variables } & Value & Unit \\
\hline Service frequency & 0.15 & $1 /$ month \\
Market reference waiting time $\left(\tau_{\mathrm{MR}}\right)$ & 2 & Months \\
Revenue per service & 1 & \$/service \\
Capacity cost $\quad$ Delays & 0.5 & \$/month \\
\hline Capacity delivery delay & Value & Unit \\
Capacity retirement delay & 4 & Months \\
Perception time of current customers $\left(1 / \varphi_{\mathrm{c}}\right)$ & 2 & Months \\
Perception time of potential customers $\left(1 / \varphi_{\mathrm{p}}\right)$ & 2 & Months \\
\hline \hline
\end{tabular}

Table 1. Initial model configuration

Upon arrival, the subjects were allocated to a PC and separated from their neighbours by another PC. Communication between the subjects was forbidden. Once seated, they were provided with written instructions and a consent form, which they had to sign before starting the experiment. The instructions provided an explanation of the system they had to manage during the experiment and contained the information they had available to carry out their task. They were introduced to the interface and the tasks they should perform during and after the experiment. The written instructions are given in the appendix $\mathrm{C}$.

The subjects' objective was to maximise the cumulative profits of the garage over 100 experimental periods (i.e., months) by satisfying their existing customers and attract new ones. Subjects had to decide each period how much capacity to add or to remove. When subjects decided to adjust capacity they could use the sliders in the first square (Your decisions) of Figure 3 or write their decision in the text box on the right side of the sliders.

To help subjects make these decisions they were provided with information about the system (see Figure 3). They knew the number of customers currently waiting for service or whose car was currently being serviced (referred to as the backlog of customers), their current service capacity, and 
its utilisation rate. This information was also given in a graphical way so that they could observe its evolution. Subjects were also aware that the arrival-rate is sensitive to the waiting time. Additionally they could observe the current revenue, the capacity costs, the profit per period and the cumulative profit.

The experiment ended once the subject made the last decision in period 100 or when the available service capacity reached 0 , i.e., the subject shut down his facility. Three subjects closed down the facility before period 100. These subjects were not considered in the statistical analysis. Subjects worked at their own pace, without time pressure. All subjects completed the experiment in less than 1.5 hours, with the average duration being about one hour.

\section{Experimental Results}

In this section, we first provide a general overview of the results. Visual inspection reveals three groups of subjects whose decisions yield similar behavioural patterns, of respectively eleven, thirteen and nine subjects. Figure 4 illustrates the capacity adjustment decisions (left column) and the evolution of the backlog and the available service capacity over the 100 periods (right column) for a typical subject from each group. Negative capacity adjustment decisions represent capacity retirement decisions.

During the first five periods, the backlog increases for the three subjects. This rise is independent of the subjects' decisions because of the initial conditions which imply a 2 month waiting time for the initial customer backlog. This waiting time corresponds to the market reference and the initial perception of both current and potential customers, and thus attracts new customers to the facility during the first periods. As service capacity cannot be increased instantaneously, the backlog of customers rises. Consequently, the waiting time increases. This affects the customers' perceptions, resulting in fewer arrivals, and a drop in the backlog starting in period 6, as shown in Figure 4. Most subjects initially decide to increase capacity; thereafter, they overreact to the decreasing backlog by removing capacity. We can interpret these first reactions as a learning process in which subjects are trying to understand the system behaviour. After the first few periods, the three groups of subjects start to behave differently. 

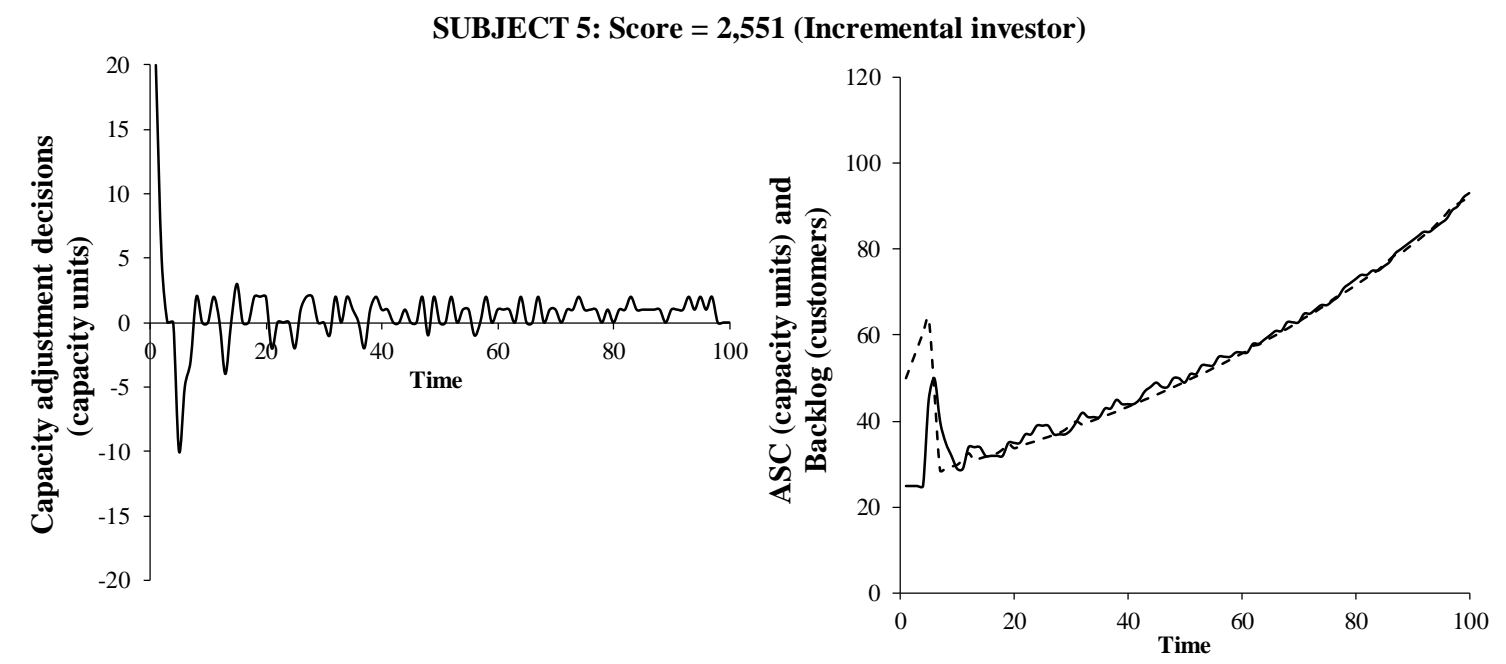

SUBJECT 12: Score = 2,207 (Lumpy investor)
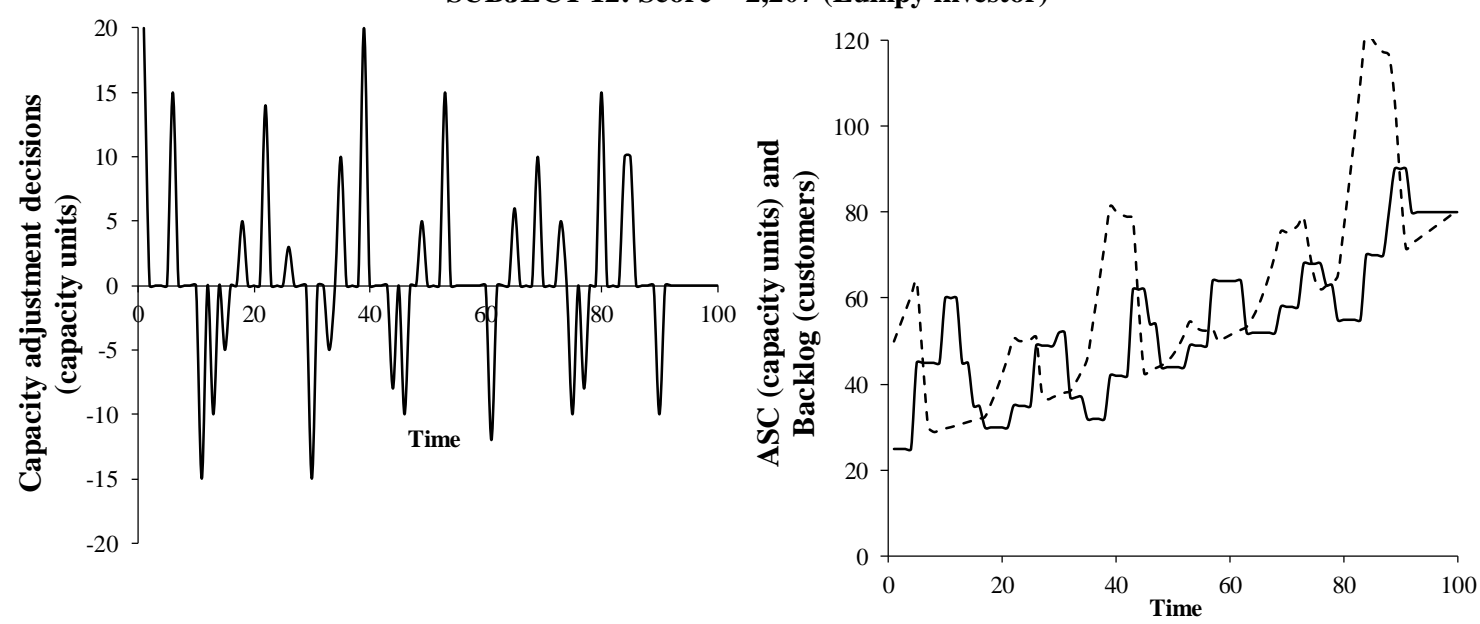

SUBJECT 3: Score $=719$ (Reactive investor)
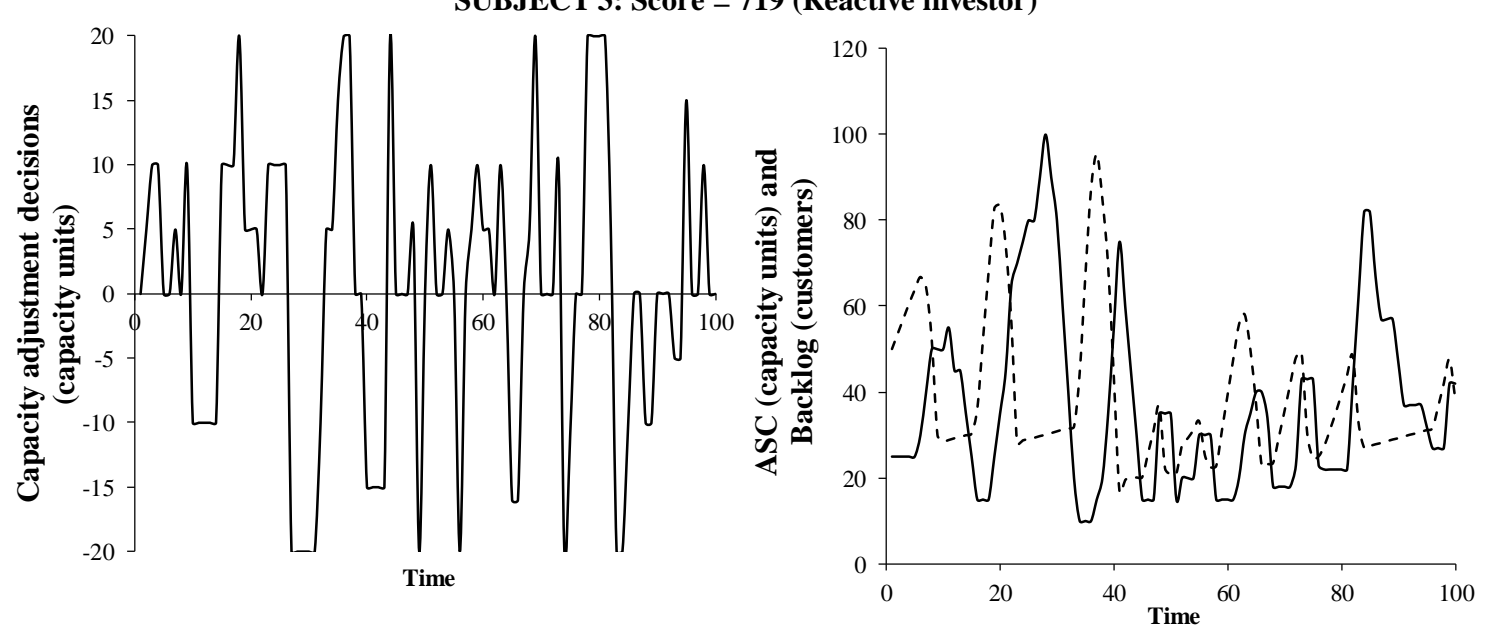

Figure 4. Illustration of three typical behaviours.

The first group is composed of those subjects who, after the transition, switch to making small incremental capacity adjustments (e.g., Subject 5 in Figure 4). We therefore call these subjects "incremental investors". Most of their decisions concern capacity orders (i.e., positive capacity adjustment decisions). Consequently, the garage's available service capacity and the backlog follow 
similar exponential growth paths over time; the waiting time thus remains stable and the garage attracts more and more customers. We infer that these subjects learn quickly; they achieved the higher scores in the experiment.

The second group (e.g., Subject 12 in Figure 4) represents those subjects who, after the transition, make fewer, but more aggressive, capacity adjustment decisions compared to the first group. Moreover, they continue to overreact to changes in the backlog. Hence, these subjects alternate capacity increase and decrease decisions (the capacity adjustment decisions are positive and negative as can be seen in Figure 4). This behaviour results in an oscillating pattern for both the available service capacity and the backlog. The subjects in this group are categorised as "lumpy investors": they decide to add chunks of capacity when the backlog increases. However, the high average waiting time affects customers' perception, inducing some of them to leave. Consequently, when the capacity increase materialises (after the delays involved in the implementation process) the backlog of customers is already decreasing and the new capacity speeds up this process. The opposite logic then applies: as the backlog is low, the subjects decide to decrease capacity. Given that the capacity orders are generally higher than the retirement decisions, the available service capacity increases over time, but more slowly and less regularly than for the first group.

The third group consists of subjects who, even after the transition period, continue to overreact significantly in both directions to the evolution of the backlog (e.g., Subject 3 in Figure 4). We label these subjects "reactive investors". Given this behaviour, we conclude that this group of subjects is unable to handle the delay structure inherent to the system. They performed poorly, achieved the lowest payoffs and three of these subjects reached zero service capacity before the end of the experiment. These three subjects were excluded from the analysis, leaving only six reactive investors.

Figure 5 shows the autocorrelation function (ACF) of the capacity adjustment decisions for two subjects of each type. The lags outside the shaded region are significantly different from zero. Nineteen subjects out of 30 have a first-order lag that is significantly greater than zero at the $5 \%$ level of significance, as illustrated in Figure 5 for subjects 3, 5, 11, and 30. This means that the decision they made at time $t$ is positively correlated with the one they made one period earlier (i.e., time $t-1$ ). These 19 subjects include all six reactive investors, seven out of 11 incremental investors and only six out of 13 lumpy investors. All of these 19 subjects exhibit at least one significant higher-order lag; in particular, 7 subjects exhibit a positive second-order auto-correlation (3 reactive investors, 3 incremental investors and 2 lumpy investors). 


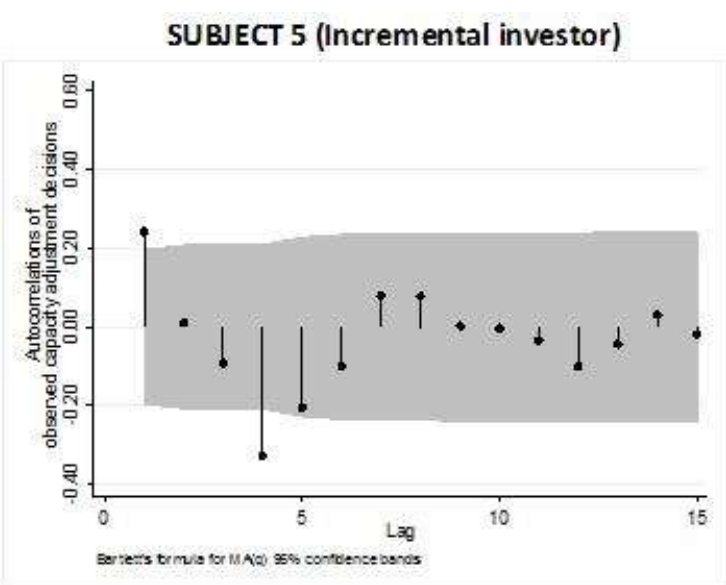

SUBJECT 12 (Lumpy investor)

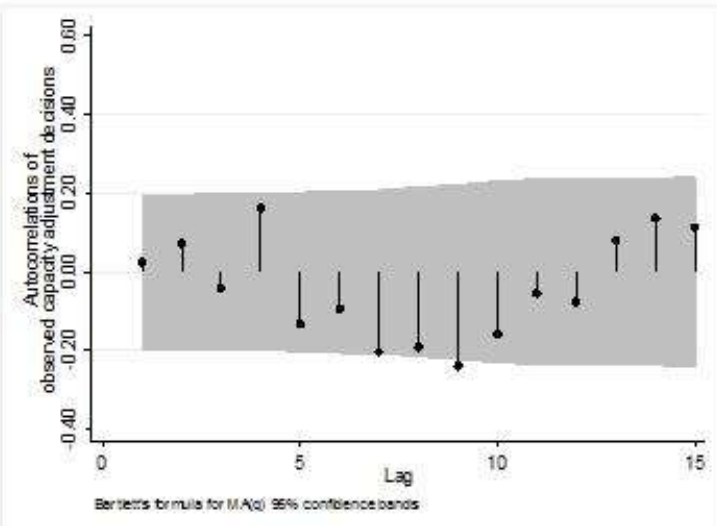

SUBJECT 03 (Reactive investor)

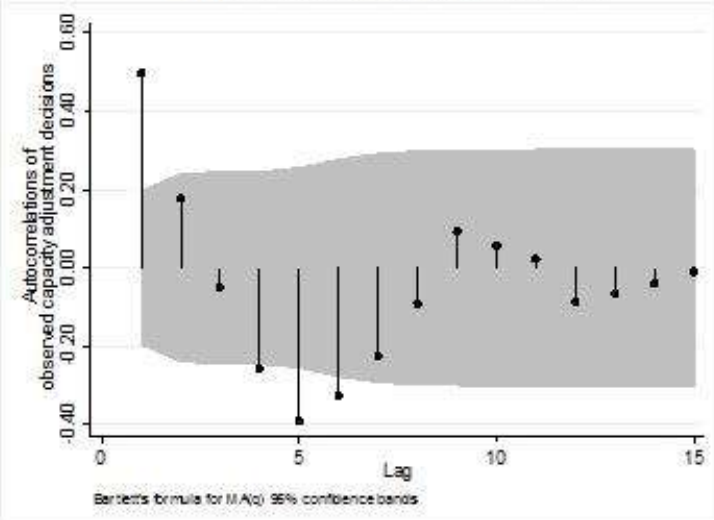

SUBJECT 11 (Incremental investor)

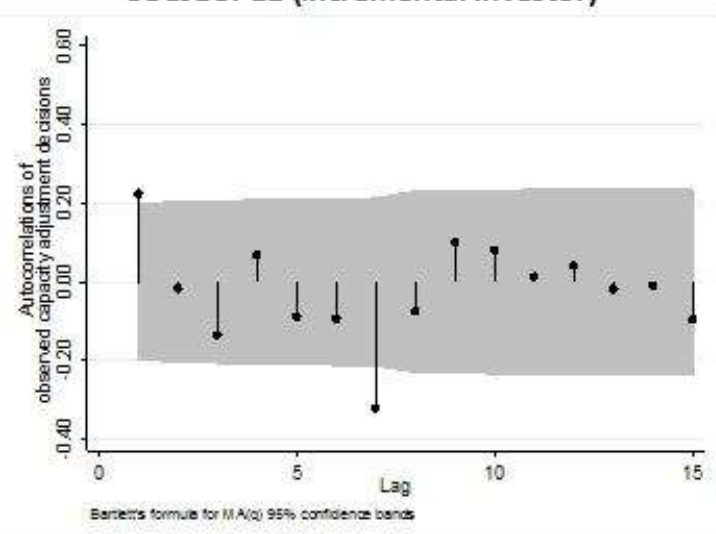

SUBJECT 18 (Lumpy investor)

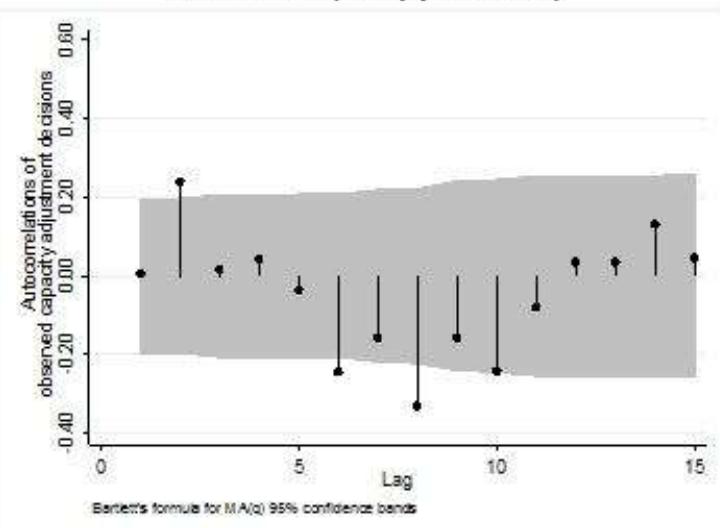

SUBJECT 30 (Reactive investor)

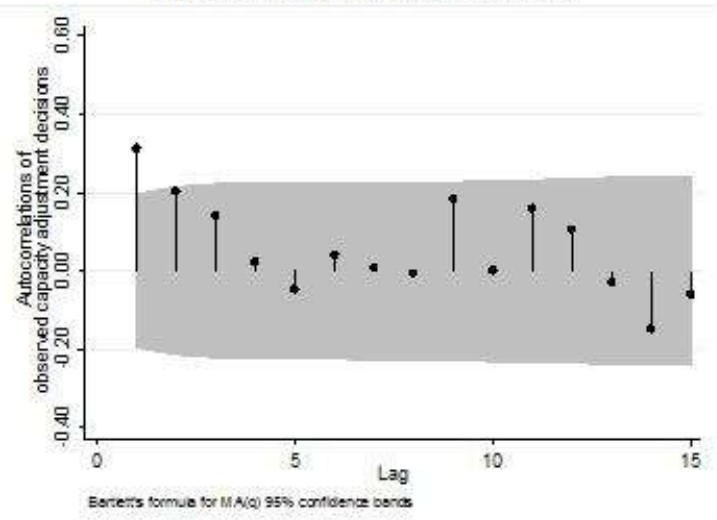

Figure 5. Correlograms of observed capacity decisions of selected subjects.

Of the remaining 11 subjects, 7 have at least one significant higher-order lag. For instance, the first-order lags of subjects 12 and 18 (lumpy investors) are not significantly different from zero, but they have other significant higher-order lags: the ninth-order lag of the ACF of subject 12 and the second, sixth and eighth-order lags of subject 18. Similarly, subjects 3, 5 and 11 also present significant higher-order lags. For only four subjects out of the 30 are all the lags non-significant. Three of these are incremental investors and one is a lumpy investor. There are 16 subjects with at least one significant negative higher-order lag. These include 8 out of the 13 lumpy investors, 3 out of 6 lumpy 
investors and only 5 out of 11 incremental investors. Recall that there are significant delays in the system: capacity decisions only materialise after 2 (increase) or 4 (decrease) periods, and it takes time for customers to update their expectations. The higher-order auto-correlations are thus not a surprise.

These significant higher-order lags constitute evidence of the presence of oscillating patterns in the subjects' decisions, as was illustrated in Figure 4. In particular, capacity adjustment decisions of the reactive customers are characterised by a much more pronounced oscillatory pattern than those of the lumpy investors, while most-incremental investors only exhibit minor oscillations after the first few periods. Consequently, the available capacity of the reactive investors also exhibit oscillatory patterns. The available capacity of most incremental and lumpy managers exhibits an increasing trend; a fairly smooth growth for incremental investors compared to a more oscillatory growth for lumpy investors. The autocorrelation analysis of subjects' decisions suggests that we should incorporate managers' previous decisions when modelling their decision-making process in a queuing management context.

In this experiment, managers were encouraged to focus exclusively on customer satisfaction: the lower the waiting time, the more customers the facility attracts, and the more profitable it should be as capacity adjustments cause no costs. We have also experimented with a variation where such adjustments are costly: managers incur a cost of $\$ 1 /$ unit whenever they increase or decrease capacity. This corresponds to the monthly revenue a unit of capacity generates if in use.

Thirty subjects took part in this experiment. We observed the same behavioural patterns, but with a decrease in the fraction of reactive customers, from $27 \%$ to $13 \%$. The remaining $87 \%$ of subjects were split equally between incremental and lumpy investors. Despite this change in proportions, we were unable to reject the hypothesis that both subject groups (with and without capacity adjustment cost) make on average the same capacity adjustment decisions (Mann-Whitney-Wilcoxon test (Newbold, 1988), P-value $=0.2640>0.01$ ). We can thus conclude that our results are robust with respect to the introduction of a realistic capacity increase or dismantling cost.

\section{Modelling the Capacity Adjustment Decisions}

Based on the exploratory analysis of subject's behaviour we propose a heuristic to model the way subjects made their decisions: how much capacity do managers order or retire every period as a function on the available information. This heuristic is formulated as a multivariate regression model, which captures the autocorrelation observed in the capacity adjustment decisions of the subjects. First, we estimate the parameters of this regression model. Next, we incorporate this heuristic in the original SD model upon which the experiment is based. We compare the simulated behaviour to the one observed in the laboratory. 
The goal of the manager is to maximise profits, which requires adjusting service capacity so as to provide a satisfactory service level, while avoiding overcapacity. While the manager does not know with certainty the demand of his facility over the next periods, he does know the number of customers who currently have an appointment (i.e., the backlog). We therefore hypothesise that the manager determines his desired service capacity $\left(D C_{t}\right)$ by combining his most up-to-date information regarding the backlog of work $\left(Q_{t-1}\right)$ with a market reference of the waiting time $\left(\tau_{M R}\right)$. This reference waiting time is the desired response time which the manager wishes to achieve. We hypothesise that the managers' desired service capacity is proportional to the backlog:

$$
D C_{t}=\delta Q_{t-1}
$$

where $1 / \delta$ represents the reference average waiting time of the manager. Once the manager knows his desired service capacity, he compares this value to what he considers to be his available service capacity in order to decide how much service capacity to order or to withdraw. When the desired capacity exceeds the current capacity, the manager decides to order capacity. When the opposite occurs, he decides to remove capacity.

Subjects should account for their previous decisions, which have not yet been implemented, when estimating their available service capacity. These not-yet-implemented capacity adjustments $\left(\Delta C_{t}\right)$ are given by the difference between the capacity on order $\left(C O_{t}\right)$ and the capacity to be retired $\left(C b R_{t}\right)$ at time $t$ :

$$
\Delta C_{t}=C O_{t}-C b R_{t}
$$

Once all these past decisions $\left(\Delta C_{t}\right)$ will have been implemented, the future service capacity $\left(F S C_{t}\right)$, will equal:

$$
F S C_{t}=A S C_{t}+\Delta C_{t}
$$

Previous research in capacity management suggests that decision makers often take into account only a fraction of the supply line when managing capacity adjustments (Sterman, 1989a, 1989b). Hence, we incorporate the parameter $\psi$ to represent the proportion of the not-yet-implemented previous decisions (i.e., the capacity supply-line) which managers account for when taking their next decision. We call this parameter the "coherence factor". Thus, the estimated future service capacity $\left(\overline{F S C}_{t}\right)$, which managers consider when taking capacity adjustment decisions, is modelled as follows:

$$
\overline{F S C}_{t}=A S C_{t}+\psi \Delta C_{t}
$$

The perceived gap $\left(P G a p_{t}\right)$ between the desired service capacity and the estimated future service capacity the manager faces each period is: 


$$
P G a p_{t}=D C_{t}-\overline{F S C}_{t}
$$

Replacing $D C_{t}$ and $\overline{F S C}_{t}$ using equations (4) and (7) yields:

$$
P G a p_{t}=\delta Q_{t-1}-\left(A S C_{t}+\psi \Delta C_{t}\right)
$$

A manager might not wish to, or be able to, close this gap immediately as it is based on a perceived need. Let $\chi$ denote the speed at which the manager chooses to close this perceived gap, i.e., how aggressive is he when making decisions. We define the capacity adjustment decision $\left(C A D_{t}\right)$ as $C A D_{t}=\chi P G a p_{t}$. Combining this with Equation (9) yields:

$$
C A D_{t}=\chi\left[\delta Q_{t-1}-\left(A S C_{t}+\psi \Delta C_{t}\right)\right]
$$

where $\chi$ must be between 0 and 1 . This adjustment involves either an increase in capacity (when $C A D_{t}>0$ ), a decrease in capacity (when $C A D_{t}<0$ ), or leaving capacity unchanged (when $C A D_{t}=0$ ). Defining $\delta^{\prime}=\chi \delta$ and $\psi^{\prime}=\chi \psi$, we obtain:

$$
C A D_{t}=\delta^{\prime} Q_{t-1}-\chi A S C_{t}-\psi^{\prime} \Delta C_{t}
$$

The parameters $\delta^{\prime}, \chi$ and $\psi^{\prime}$ are estimated using a multivariate linear regression without intercept. The coherence factor $\psi$ should be a non-negative number. If $\psi^{\prime}=\chi$, then $\psi=1$ and the subjects account fully for their not-yet-implemented decisions when taking new capacity adjustment decisions. If $0<\psi<1$, subjects account for a fraction of their not-yet-implemented decisions; whereas if $\psi>1$, subjects overestimate their not-yet-implemented decisions. If $\psi=0$, the not-yet-implemented decisions are ignored. Negative values of $\psi$ are an indication of incoherent decision making. Also, given that $1 / \delta$ represents the average waiting time the manager takes as reference to estimate his desired service capacity, we expect $\delta$ ' to be non-negative.

Table 2 contains the parameter estimates (i.e., $\delta^{\prime}, \chi$ and $\psi^{\prime}$ ) together with the $p$-values of the $F$-test for the significance of the linear regression for the 30 subjects. The $F$-test indicates whether there is a linear relationship between the desired capacity adjustment and the set of variables considered, i.e., $Q_{t}$ 1, $A S C_{t}$ and $\Delta C_{t}$ (Montgomery \& Runger, 2003). Unlike the $t$-test, which assesses if the individual effects of these variables are significant, the $F$-statistic is used to test the null hypothesis that these effects are simultaneously equal to zero. The $R^{2}$ is not included in this analysis, given that we are considering a model without intercept. Hence, the analysis of this measure is not appropriate (Greene, 2002; Chatterjee \& Hadi, 2006).

The hypothesis that all parameters of the model are simultaneously equal to zero is rejected for all but 2 subjects, as indicated by the $p$-values of the $F$-test. In most of the cases, this hypothesis is 
rejected at the $1 \%$ significance level. This means that at least one of the variables $Q_{t-1}, A S C_{t}$ and $\Delta C_{t}$ contributes significantly to the model. That is, the capacity adjustment decisions can be estimated by a linear model in terms of $Q_{t-1}, A S C_{t}$ and $\Delta C_{t}$ for 28 out of 30 subjects.

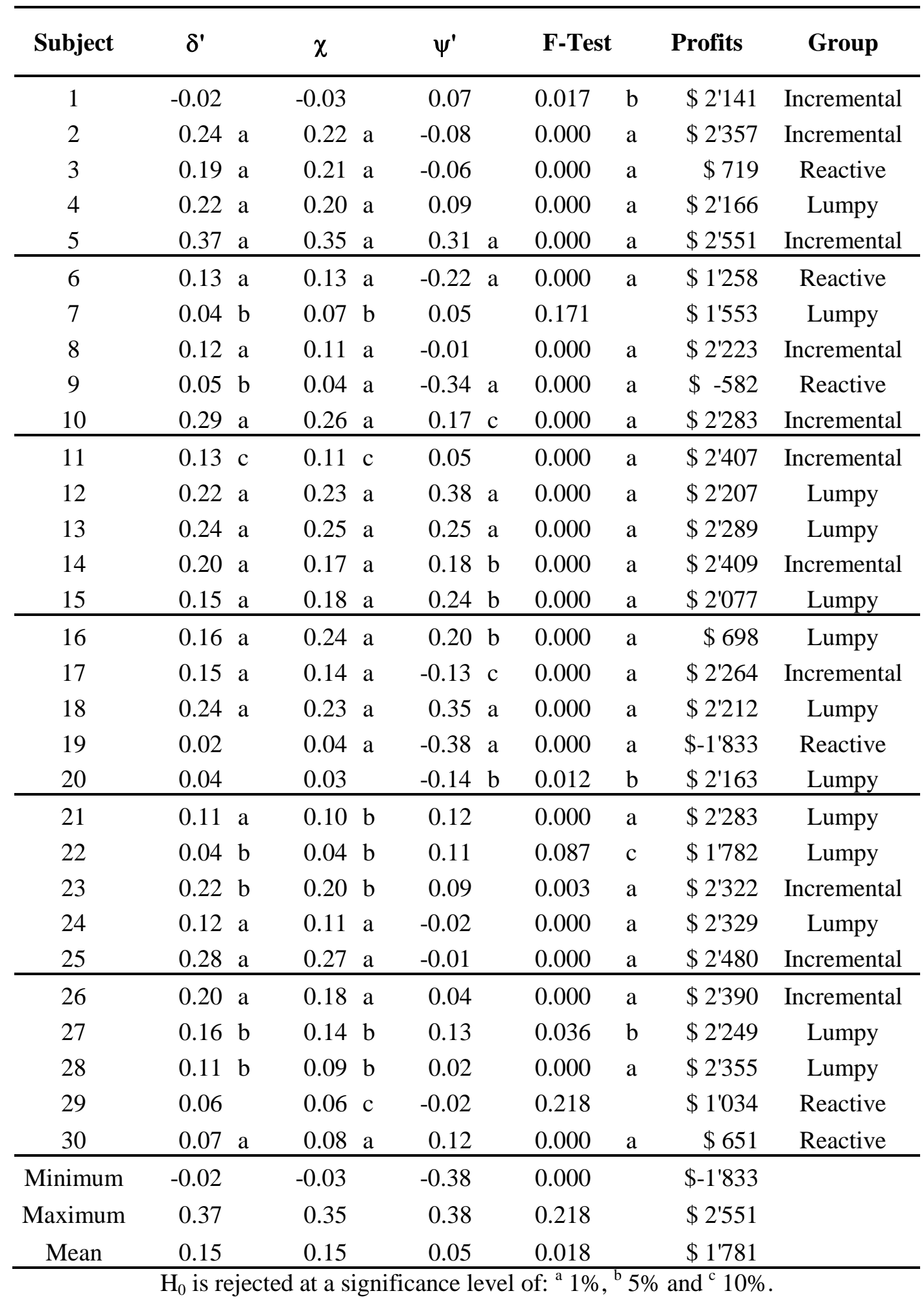

Table 2. Parameters estimates. 
Concerning the significance of the individual parameters, we can observe that the majority of the estimates for $\delta$ ' and $\chi$ are significant. Only for subjects 1 and 20, are both parameters not significantly different from zero, while for subjects 19 and 29 only $\delta$ ' is not significant. The situation is different for $\psi^{\prime}$, which is significant for less than half of all subjects. This indicates that over half the subjects totally ignore their not-yet-implemented decisions when deciding new capacity adjustments (Sterman, 1989a).

The estimated parameters are all significant for eleven subjects (i.e., about $37 \%$ of the sample). However, subjects 6, 9 and 17 have negative values for $\psi$, which is not coherent with the conditions stated above. Table 3 summarises the estimated parameters of Equation 10 (i.e., $\chi, \delta$ and $\psi$ ) for the subjects whose parameters are all significant in Table 2 and satisfy all conditions stated above. In the remainder of the paper, we focus our discussion on these remaining eight subjects, listed in Table 3.

\begin{tabular}{clllll}
\hline Subject & \multicolumn{1}{l}{$\boldsymbol{\delta}$} & \multicolumn{1}{l}{$\chi$} & $\boldsymbol{\psi}$ & \multicolumn{1}{l}{ Profits } & Group \\
\hline 5 & 1.08 & 0.35 & 0.89 & $\$ 2,551$ & Incremental \\
10 & 1.09 & 0.26 & 0.64 & $\$ 2,283$ & Incremental \\
12 & 0.98 & 0.23 & 1.68 & $\$ 2,207$ & Lumpy \\
13 & 0.99 & 0.25 & 1.01 & $\$ 2,289$ & Lumpy \\
\hline 14 & 1.15 & 0.17 & 1.03 & $\$ 2,409$ & Incremental \\
15 & 0.84 & 0.18 & 1.37 & $\$ 2,077$ & Lumpy \\
16 & 0.67 & 0.24 & 0.81 & $\$ 698$ & Lumpy \\
18 & 1.02 & 0.23 & 1.49 & $\$ 2,212$ & Lumpy \\
\hline Minimum & 0.67 & 0.17 & 0.64 & $\$ 698$ & \\
Maximum & 1.15 & 0.35 & 1.68 & $\$ 2,551$ & \\
Mean & 0.98 & 0.24 & 1.12 & $\$ 2,091$ & \\
\hline
\end{tabular}

Table 3. Subjects with significant estimated parameters of the decision rule (Equation 10).

The proposed heuristic captures the behaviour of $27 \%$ of the incremental investors (i.e., 3 out of 11) and $38 \%$ of the lumpy investors (i.e., 5 out of 13 ), but is unsuitable for all the reactive investors. Recall that $1 / \delta$ is the waiting time which the manager wishes to guarantee to his customers, i.e., it is the reference waiting time the manager uses to estimate his desired service capacity (recall Equation 4). Given that all values of $\delta$ in Table 3 exceed 0.5 , we conclude that subjects consider a reference waiting time lower than the market reference, which is equal to 2 months. The subjects' reference waiting times range from 0.87 to 1.49 months. On average, they consider a reference waiting time of just over one month. In general, incremental investors contemplate a reference waiting time below 1 month, while for lumpy investors this measure ranges between 1 and 1.5 months, except for subject 
18. This indicates that incremental investors are more pro-active than lumpy investors in attracting more customers by seeking to offer lower waiting times. A change in observed backlog induces a more significant adjustment in desired capacity from incremental investors than from lumpy investors. This result is coherent with the way subjects characterised as incremental investors actually made their decisions (see Figure 4) and the performance they achieved.

The estimates for $\chi$ indicate that subjects are very cautions (i.e., slow decision makers) when making capacity adjustments based on their perceptions, since the values of this parameter are quite low, the highest being 0.35 . This means that subjects decide to adjust capacity by at most $35 \%$ of the discrepancy they perceive between the desired service capacity and the future service capacity.

The eight subjects included in Table 3 are the only ones who account, at least to some extent, for their not-yet-implemented decisions. The rational value of $\psi$ is 1 , indicating that subjects correctly incorporate the capacity supply-line when making capacity adjustment decisions. Only two subjects have a parameter estimate close to 1 . Three subjects have parameter values ranging from 0.64 to 0.89 ; they thus account partially for these not-yet-implemented decisions, which is coherent with the literature (e.g., Sterman, 1989a). More surprisingly, three subjects have much higher values, ranging from 1.37 to 1.68 , implying that they overestimate their not-yet-implemented decisions.

Figure 6 compares the capacity adjustments resulting from simulating the estimated decision rules to the experimental results for three subjects. The decision rule closely matches the decisions taken by subjects of the first group (see for instance subject 5 in Figure 6). Regarding lumpy investors (e.g., Subjects 12 and 13), the decision rule captures the oscillating pattern of their decisions and the instability of the available service capacity fairly well, but not the amplitude and the period. 

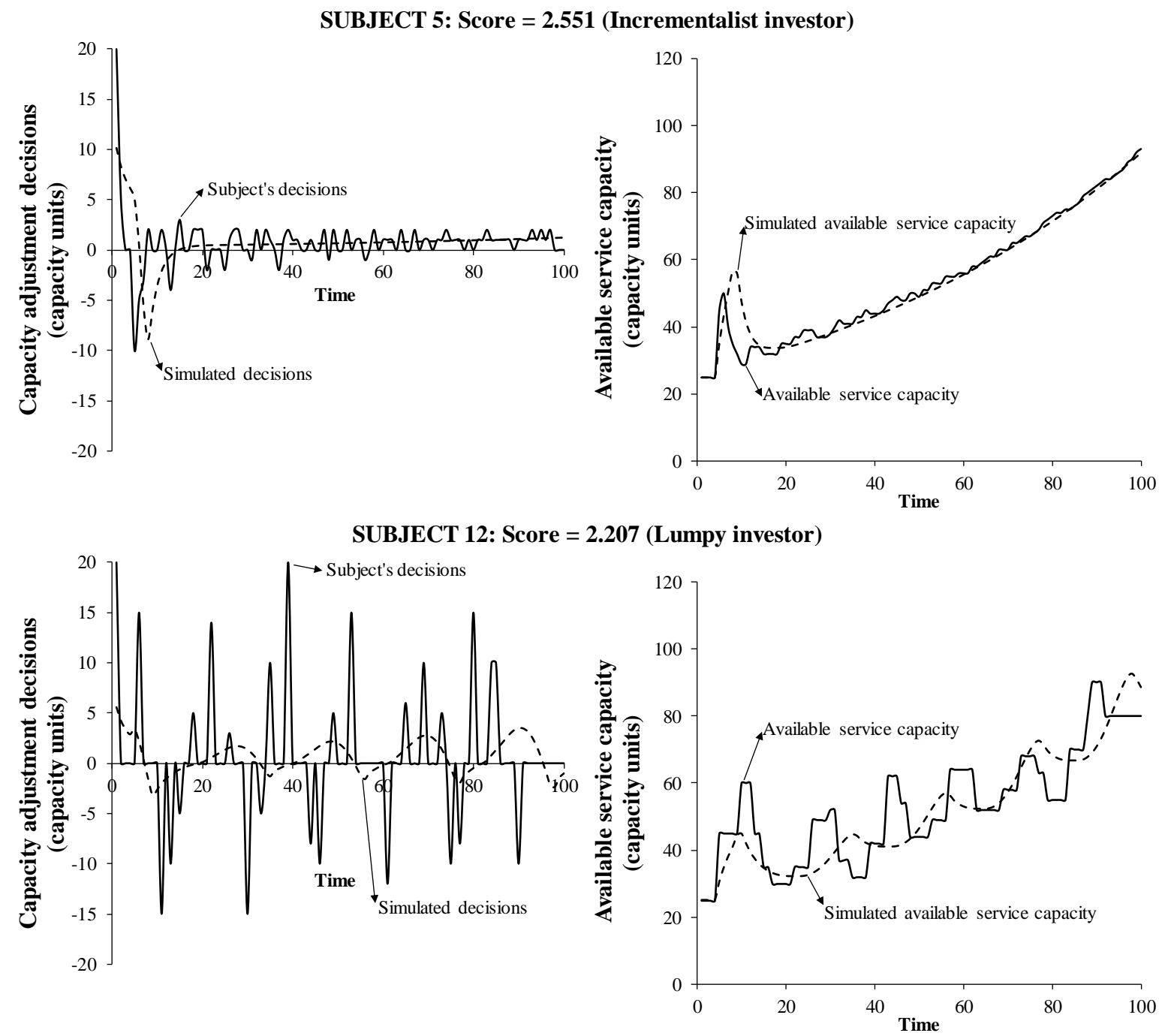

SUBJECT 13: Score $=2.289$ (Lumpy investor)
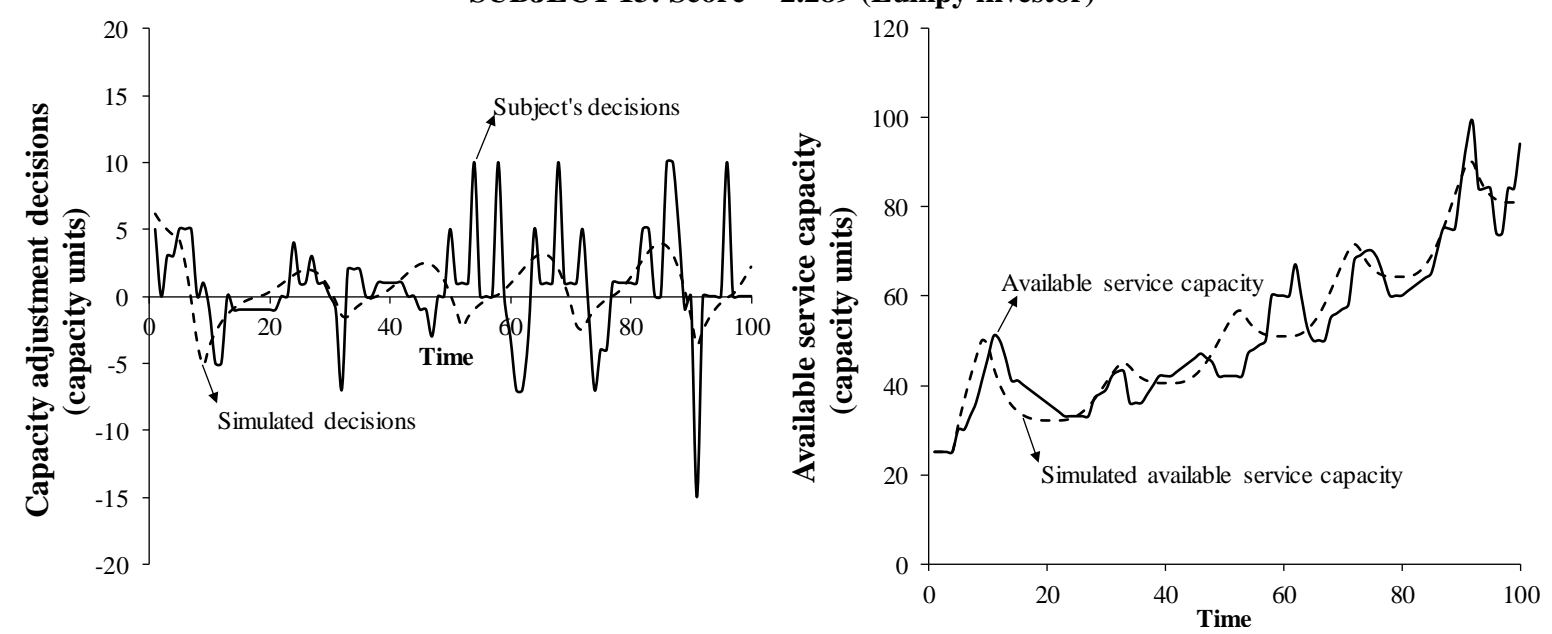

Figure 6. Comparison of experimental and estimated capacity decisions and available service capacity for three subjects.

\section{Conclusions}

We have used a laboratory experiment to explore managers' decisions in service facility systems, 
aiming to test the insights derived from a simulation model by van Ackere et al. (2013). Their model represents a stylised capacity decision problem, where managers use a simple decision rule to adjust capacity based on current backlog and expected future demand.

In our experiments we found that the behaviour of the subjects can be classified into three broad types: (i) incremental investors, who make small, almost continuous, adjustments to the capacity of the facility, (ii) lumpy investors, who make relatively large, but less frequent, capacity changes and (iii) reactive investors, who make what looks like large random adjustments, both when increasing and decreasing capacity. This observation is robust to the inclusion of a cost to add or dismantle capacity. Our results point to the need to consider different decision rules to capture the behaviour of these three different groups, i.e., the differences in behaviour cannot be explained by a different parameterisation of a single common rule.

Our analysis showed that the capacity adjustment decisions made by about two thirds of the subjects are positively correlated with the (not yet implemented) decisions taken one period earlier. This implies that managers' decisions do not depend solely on their perceived capacity utilisation: instead they are to some degree influenced by their previous decisions. Still, the decision rule we estimate based on these observations indicates that relatively few subjects take a significant fraction of the not-yet-implemented decisions into account. Subjects who do account for this capacity supply-line when making decisions tend to out-perform the others.

The reactive investors are the only group whose performance does not improve over time: they overreact strongly and erratically to both positive and negative changes in the customer backlog. The magnitude of their decisions even increases during the second half of the experiment, to the point where some subjects unintentionally close down their facility before the end of the experiment. We conclude that these subjects are unable to handle the delay structure inherent to the system.

Generally, subjects in the incremental group perform better than those of the other two groups. They build up their capacity slowly, gradually capturing more customers, avoiding sudden shocks to the system. The behaviour of the other two groups (alternating large capacity additions and removals) creates the risk of capacity adjustments being out of phase with the evolution of the customer base: the facility grows when the customer base contracts, and vice versa.

While we concluded that the incrementalists achieved the best performance, one should be aware that this strategy is only realistic in environments where it is possible to make repeated, small capacity adjustments, for instance opening additional tills in a supermarket. Such an approach is not feasible when considering investments in infrastructure where capacity must be added in discrete chunks, e.g., tunnels or power plants.

It is well known that being reactive in systems with significant delays can lead to over-reaction. 
This has been documented, for instance, in multi-echelon supply chains (Mosekilde \& Larsen, 1988; Sterman, 1989a). However, it is worth noticing that even in a simple system as the one used in this experiment, which only has one echelon, we observe similar consequences. This shows clearly that even in the most simple systems, delays and feedback create significant problems for the majority of subjects.

Our results have at least two implications for the design of facility systems. Firstly, we need to make it easier for decision makers to incorporate not-yet-implemented capacity changes, both positive and negative, into their decision-making process. In our experiment, it was relatively easy for the decision maker to understand the connection between capacity and customers. In a real setting, actions by other facility owners offering the same service also influence the number of customers, adding significant complexity to the system, as the relationship between capacity and customers will be less clear. It is thus necessary to have a well-developed management information system to help the manager in his decision-making process, particularly in a fast moving environment which requires continuous adjustments. Secondly, our observations highlight the need to invest in system-redesign to shorten the lags to make the system more responsive, and thus easier to manage: rendering the consequences of the decisions easier to observe allows for faster corrective action.

The experiments reported here are a first step and can be extended in several ways. First, different values could be considered for the various delays in the model to assess their influence on the decisions and the performance of the subjects. Second, the impact of including a cost for capacity installation and dismantling deserves further analysis. We only considered a symmetric per unit cost; considering an asymmetric cost structure and / or a fixed cost per decision could affect the three investor types in different ways.

\section{Acknowledgement}

The work leading to this paper was made possible by the support received from the Swiss National Science Foundation, Research Grants 100012-116564 and 100014-126584. We thank three anonymous referees for their valuable comments.

\section{References}

Allon, G., \& Federgruen, A. (2008). Service competition with general queueing facilities. Operations Research, 56 (4), 827-849. doi: 10.1287/opre.1080.0545

Arango Aramburo, S., Castañeda Acevedo J.A., \& Olaya Morales, Y. (2012). Laboratory experiments in the system dynamics field. System Dynamics Review, 28(1), 94-106. doi: 10.1002/sdr.472.

Arango, S., \& Moxnes, E. (2012). Commodity cycles, a function of market complexity? Extending the cobweb experiment. Journal of Economic Behaviour \& Organization, 84 (1), 321-334, 
doi:10.1016/j.jebo.2012.04.002.

Barlas, Y. (1996). Formal aspects of model validity and validation in system dynamics. System Dynamics Review, 12 (3), 183-210.

Bassamboo, A., \& Randhawa, R. S., (2010). On the accuracy of fluid models for capacity sizing in queueing systems with impatient customers. Operations Research, 58 (5), 1398-1413

Chatterjee, S., \& Hadi, A.S. (2006). Regression analysis by example (4th ed.). New York, NY: John Wiley \& Sons.

Choi, S., \& Messinger, P.R. (2016). The role of fairness in competitive supply chain relationships: An experimental study. European Journal of Operational Research, 251 (3), 798-813. doi:10.1016/j.ejor.2015.12.001.

Forio Online Simulations, http://forio.com/simulate.

Friedman, D., \& Sunder, S. (1994). Experimental methods: a primer for economists (1st ed.). Cambridge, MA: Cambridge University Press.

Greene, W.H. (2002), Econometric analysis (5th ed.). New Jersey, NJ: Prentice Hall.

Kampmann, C.E., \& Sterman, J.D. (2014). Do markets mitigate misperceptions of feedback? System Dynamics Review, 30 (3), 123-160. doi: 10.1002/sdr.1515.

Montgomery, D.C., \& Runger, G.C. (2003). Applied statistics and probability for engineers (3rd ed.). New York, NY: John Wiley \& Sons.

Morecroft, J.D.W. (2015). Strategic modelling and business dynamics. (2nd ed.). Chichester, UK: John Wiley \& Sons.

Mosekilde, E., \& Larsen, E.R. (1988). Deterministic Chaos in the Beer Production-Distribution Model. System Dynamics Review, 4 (1-2), 131-147. doi: 10.1002/sdr.4260040108.

Moxnes, E. (2000). Not only the tragedy of the commons: misperceptions of feedback and policies for sustainable development. System Dynamics Review, 16 (4), 325-348. doi: 10.1002/sdr.201.

Myrtveit, M., (2005). The World Model Controversy. In: Working Papers in System Dynamics, W.P.I.S. (Ed.). Department of Geography, University of Bergen, ISSN 1503-4860.

Naor, P. (1969). The Regulation of Queue Size by Levying Tolls. Econometrica, 37(1), 15-24.

Newbold, P. (1988). Statistics for business and economics (2nd ed.). Englewood Cliffs, NJ: Prentice Hall.

Paich M., \& Sterman, J.D. (1993). Boom, bust, and failures to learn in experimental markets. Management Science, 39 (12), 1439-1458.

Pazgal, A.I., \& Radas, S. (2008). Comparison of customer balking and reneging behavior to queueing 
theory predictions: An experimental study. Computers \& Operations Research, 35 (8), 2537 2548. doi:10.1016/j.cor.2006.12.027.

Rapoport, A., Stein, W.E., Parco J.E., \& Seale D.A. (2004). Equilibrium play in single-server queues with endogenously determined arrival times. Journal of Economic Behavior \& Organization, 55 (1), 67-91. doi: 10.1016/j.jebo.2003.07.003.

Rapoport, A., Stein, W.E., Mak, V., Zwick, R., \& Seale, D.A. (2010). Endogenous arrivals in batch queues with constant or variable capacity. Transportation Research Part B, 44 (10), 1166-1185. doi: 10.1016/j.trb.2010.01.005.

Seale, D.A., Parco, J.E., Stein, W.E., \& Rapoport, A. (2005). Joining a queue or staying out: effects of information structure and service time on arrival and staying out decisions. Experimental Economics, 8 (2), 117-144. doi: 10.1007/s10683-005-0872-1.

Smith, V.L. (1982). Microeconomic systems as an experimental science. The American Economic Review, 72 (5), 923-955.

Stein, W.E., Rapoport, A., Seale, D.A., Zhang, H., \& Zwick, R. (2007). Batch queues with choice of arrivals: Equilibrium analysis and experimental study. Games and Economic Behavior, 59 (2), 345-363. doi: 10.1016/j.geb.2006.08.008.

Sterman, J. D. (1985). A behavioral model of the economic long wave. Journal of economic behavior \& organization, 6(1), 17-53.

Sterman, J.D. (1989a). Modeling managerial behavior: misperceptions of feedback in a dynamic decision making experiment. Management Science, 35 (3), 321-339. doi: 10.1287/mnsc.35.3.321.

Sterman, J.D. (1989b). Deterministic chaos in an experimental economic system. Journal of Economic Behavior \& Organization, 12 (1), 1-28. doi: 10.1016/0167-2681(89)90074-7.

Sterman, J.D. (2000). Business Dynamics: Systems Thinking and Modeling for a Complex World (1st ed.). Chicago, IL: Irwin-McGraw Hill.

van Ackere, A., Haxholdt C., \& Larsen E.R. (2013). Dynamic Capacity Adjustments with Reactive Customers. Omega, 41 (4), 689-705. doi:10.1016/j.omega.2012.09.007.

Villa, S., Gonçalves, P., \& Arango, S. (2015). Exploring retailers' ordering decisions under delays. System Dynamics Review 31 (1-2), 1-27. doi: 10.1002/sdr.1527.

Wang, X., Debo, L.G., Scheller-Wolf, A., \& Smith, S.F. (2010) Design and analysis of diagnostic service centers. Management Science, 56 (11), 1873-1890. doi: 10.1287/mnsc.1100.1236

Wang, X., \& Disney, S.M. (2016). The bullwhip effect: Progress, trends and directions, European Journal of Operational Research, 250 (3), 691-701. doi: 10.1016/j.ejor.2015.07.022. 
Appendix A. Notation

\begin{tabular}{|c|c|}
\hline \multicolumn{2}{|l|}{ Variables } \\
\hline Waiting time & $W_{t}$ \\
\hline Expected waiting time & $\dot{W}_{t}$ \\
\hline Service rate & $\mu_{t}$ \\
\hline Backlog of work (i.e., queue length) & $Q_{t}$ \\
\hline Market reference of the waiting time & $\tau_{M R}$ \\
\hline Capacity on order & $\mathrm{CO}_{t}$ \\
\hline Service capacity & $S C_{t}$ \\
\hline Capacity to be retired & $C b R_{t}$ \\
\hline Available service capacity & $A S C_{t}$ \\
\hline Desired service capacity & $D C_{t}$ \\
\hline Not yet-implemented capacity adjustment decisions & $\Delta C_{t}$ \\
\hline Future service capacity & $F S C_{t}$ \\
\hline Estimated future service capacity & $\overline{F S C}_{t}$ \\
\hline Perceived gap between desired service capacity and future service capacity & PGap \\
\hline Capacity adjustment decision & $C A D_{t}$ \\
\hline \multicolumn{2}{|l|}{ Parameters } \\
\hline Potential customers' speed parameter to update their expectations & $\varphi_{\mathrm{p}}$ \\
\hline Potential customers' speed parameter to update their expectations & $\varphi_{\mathrm{c}}$ \\
\hline Reference average waiting time of the manager & $1 / \delta$ \\
\hline Coherence factor & $\psi$ \\
\hline Speed at which manager chooses to close his perceived gap & $\chi$ \\
\hline
\end{tabular}

Table A.1 Notation for variables and parameters 


\section{Appendix B. Equation listing}

To improve the legibility of the equations we use the term "customers" to refer to current customers and the term "prospects" to refer to potential customers. The abbreviation WT denotes waiting time. In the experiment, the equations prefixed by $(*)$ were replaced by a discrete delay. The model was simulated using the Euler integration method. The functions $f_{l}($.$) and f_{2}($.$) are$ monotonically decreasing S-shaped functions, details of which can be found in van Ackere et al. (2013).

Subjects' decisions: Capacity order, Decision to retire capacity

\section{Constants}

Market Growth Indicator

Prospects Perception Delay Time

Visits Per Week

Capacity Delivery Delay

\section{Benchmark}

Customers Perception Delay Time

Minimum Service Time

Capacity Retirement Delay

\section{Customer Sector}

$\frac{d \text { Customers }}{d t}=$ New Customers - Lost Customers

Eq. (B.1)

New Customers $=$

Normal Joining Rate * Customers * Impact of Prospects satisfaction on Joining *

Market Growth Indicator

Eq. (B.2)

Impact of Prospects satisfaction on Joining $=f_{1}(1 /$ Prospects Satisfaction $) \quad$ Eq. (B.3)

Prospects Satisfaction $=\frac{\text { Benc hmark }}{\text { Prospects Expected WT }}$
$\frac{d \text { Prospects Expected } W T}{d t}=\frac{\text { Current WT-Prospects Expected WT }}{\text { Prospects Perception Delay Time }}$

Lost Customers $=$ Potential Arrivals $*(1-$ Fraction Joining Queue $)$

Eq. (B.6)

Potential Arrivals $=$ Customers $*$ Visits Per Week

Eq. (B.7)

Fraction Joining Queue $=f_{2}(1 /$ Customers Satisfaction $)$

$\frac{d \text { Customers Expected } W T}{d t}=\frac{\text { Current WT-Customers Expected Wait }}{\text { Customers Perception Delay Time }}$

Customers Satisfaction $=\frac{\text { Benc hmark }}{\text { Customers Expected WT }}$ 
$\frac{d Q u e u e}{d t}=$ Arrival Rate - Service Rate

Eq. (B.11)

Arrival Rate $=$ Fraction Joining Queue $*$ Potential Arrivals

Eq. (B.12)

Service Rate $=\operatorname{Min}\left(\frac{\text { Queue }}{\text { Minimum Service Time }}\right.$, Available Service Capacity $)$

Eq. (B.13)

\section{Capacity Sector}

$\frac{d \text { Capacity on order }}{d t}=$ Capacity order - Capacity Delivery

Eq. (B.14)

(*) Capacity Delivery $=\frac{\text { Capacity on order }}{\text { Capacity Delivery Delay }}$

Eq. (B.15)

$\frac{d \text { Service Capacity }}{d t}=$ Capacity Delivery - Decision to retire capacity

Eq. (B.16)

$\frac{d \text { Capacity To Be Retired }}{d t}=$ Decision to retire capacity - Capacity Retirement

(*) CapacityRetirement $=\frac{\text { Capacity To Be Retired }}{\text { Capaci ty Retirement Delay }}$

Eq. (B.18)

Available Service Capacity $=$ Service Capacity + Capacity To Be Retired

Eq. (B.19) 


\section{Appendix C. Subjects' Instructions (Base case)}

\section{Instructions for the participants}

\section{NOTE: PLEASE DO NOT TOUCH THE COMPUTER BEFORE BEING ASKED TO DO SO}

Welcome to the experiment on decision making in a service industry. The instructions for this experiment are quite simple. If you follow them carefully and make good decisions, you may earn a certain amount of money. The money will be paid to you, in cash, at the end of the experiment. You are free to halt the experiment at any time without notice. If you do not pursue the experiment until the end, you will not receive any payment. The University of Lausanne has provided funds to support this experiment. If you have any questions before or during the experiment, please raise your hand and someone will come to assist you.

We assure you that the data we collect during the course of this experiment will be held in strict confidence. Anonymity is guaranteed; information will not be reported in any manner or form that allows associating names with individual players.

\section{Description of Experiment}

This experiment has been designed to study how managers adjust service capacity in a service facility. Below is a short explanation of the system that you will have to manage in the experiment. It is a relative simple system and you only have to make two decisions each time period (increasing capacity and/or decreasing capacity).

\section{The situation}

You are the manager of a large garage, which repairs and maintains cars. You have an existing customer base as well as many potential customers who currently are not using your services, but might consider doing so in the future. Both groups are sensitive to the waiting time.

Waiting time: is the average time between the moment a customer calls your garage to make an appointment and the time the car has been serviced. This depends on two factors, how many other customers have made reservations previously (i.e., how long is the queue) and the service capacity of the garage (i.e., how many cars can on average be serviced per time period). Due to planning constraints, this waiting time cannot be less than one month.

Customers: These customers use your garage on average every twice a year. They evaluate the expected waiting time (which is based on (an average of) the last few times they have used your garage) and compare this expected waiting time to the time they consider acceptable (the average for the industry, which is 2 months: the elapsed time between the moment a customer calls, and the 
moment he can pick up his car after servicing averages 2 months). If they are satisfied (i.e., the expected waiting time is comparable to or better than the average for the industry) they will remain your customer and return again to use your garage. If they consider that the waiting time is too long compared to the industry average they will switch to another garage.

Potential customers: These are people who might become customers if they consider that your waiting time is attractive (i.e., less than the industry average). However, given that they are currently not among your customers, they only hear about the waiting time at your place through word of mouth. Consequently, their estimate of the waiting time at your place is based on less-recent information than the estimate of your current customers. Note: the number of potential customers is unlimited.

Service Capacity: This is the number of cars the garage can service on average in one month. You, as the manager, control the service capacity of the garage, i.e., you have the possibility to increase and/or decrease capacity. However, this cannot be done instantaneously: it takes 4 months to increase capacity (e.g., ordering more tools, hiring people, acquiring more buildings, etc.) and 2 months to decrease capacity (end a lease on a building, lay off people, etc.). Note: If at some point your decisions result in a service capacity equal to zero (0), the garage will be closed and the experiment is ended.

\section{Your Task}

As the manager, you make decisions regarding any change in capacity for the garage each month. To help you make these decisions you have information about the number of customers currently waiting for service or whose car is currently being serviced (referred to as the queue), profit, the current capacity of the garage, and the capacity utilisation rate. You goal is to maximise the total profit over 100 months.

Cost and revenue information:

Profits $[E \$ /$ month $]=$ Revenue - Cost

Revenue [E\$/month] $=$ number of customers served [cars/month]*Average Price per Customer [E $\$ / \mathrm{car}]$

Average Price per Customer $=1 \$ /$ car

Cost $[\mathrm{E} \$ /$ month $]$ $=$ Service capacity [units]* Unit cost of service capacity $[\mathrm{E} \$ / \mathrm{unit} / \mathrm{month}]$

Unit cost of service capacity $=0.5 \$ /$ unit $/$ month

\section{Interface}

In front of the computer, you will have the interface where all interactions will take place. The information is the same as what we have provided in these instructions. Please ask the facilitator to have a trial run to test out the software. 


\section{Payment}

At the end of the experiment, you will receive a cash reward. This will consist of a guaranteed participation fee of $20 \mathrm{CHF}$, plus a bonus which will depend on the total profit you have achieved. This bonus will vary between 0 and 60CHF. If you do not pursue the experiment until the end, you will not receive any payment.

You will be asked to complete and sign a receipt with your name, email address, and student ID number. Thereafter, you can collect your payment. We will be happy to answer any questions you may have concerning this experiment.

If you want to participate in this experiment, please sign the consent form on your desk. This form must be signed before the start of the experiment.

If you have no further questions, please ask the experiment facilitator to begin. Good luck and enjoy the experiment. 